\title{
Teaching Mechatronics to Non-traditional Mechanical Engineering Students - An Adaptive Approach
}

\author{
https://doi.org/10.3991/ijep.v11i3.15833 \\ Cheryl Q. Li \\ University of New Haven, West Haven, USA \\ cli@newhaven. edu
}

\begin{abstract}
The mechanical engineering program at our university has adopted an integrated curriculum, with the first-two years based on multidisciplinary engineering foundation spiral courses across the college, and the lasttwo years following traditional mechanical engineering courses within the home department. This paper presents how we introduce the broad field of mechatronics to non-traditional mechanical engineering students via a single technical elective course. Students enrolled in mechatronics usually demonstrate a wide range in knowledge and skill preparation, especially in the areas of electronics and programming. Such diversity of backgrounds, in addition to the breadth of topics typically associated with mechatronics, impose a great challenge to the teaching of the course. In this empirical investigation, we propose an adaptive approach to respond to the challenge. Two stages of adaptation are involved in this teaching approach. At the stage of course design, design-loop adaption is applied to restructure the course contents based on a starting point assessment. During the process of course delivery, task-loop adaption is implemented based on the dynamic assessment of student knowledge state. By replacing the common one-fixed-content-fit-all teaching approach to an adaptive one, we can engage the less prepared and less enthusiastic students while maintaining the interest of the majority in class. Qualitative analysis of the course evaluation results have shown that the adaptive teaching approach has achieved success in several dimensions.
\end{abstract}

Keywords-Mechatronics, adaptive teaching, hands-on approach, engineering education

\section{Introduction}

As the demand for "work-ready" graduates in the workspace is growing, mechatronic engineers are highly sought-after in the job market. Recognizing the importance of teaching mechatronics, the mechanical engineering department at University of New Haven introduced a concentration in mechatronics a few years ago. The concentration consists of a required course, Instrumentation Lab, and three electives, ideally in the order of Introduction to Mechatronics, Dynamics and Control, and Introduction to Robotics. This paper presents the design and pedagogical philosophy of the first elective in the sequence: Introduction to Mechatronics (IntroM). 
The mechanical engineering program at our university consists of an integrated curriculum, with the first-two years based on multidisciplinary engineering foundation spiral courses across the college [1], and the last-two years following traditional mechanical engineering courses within the home department. In the foundation spiral curriculum, students develop a conceptual understanding of engineering basics in a series of courses which cover typical engineering topics. Different from traditional engineering curricula, however, a single course in this spiral curriculum contains a mix of these topics presented in a multidisciplinary context. The courses are designed in such a way that the key concepts will be introduced at several points along the "spiral" of the curriculum, adding depth and complexity at each step.

The pedagogical philosophy of the spiral curriculum originates from the educational theory developed by Bruner [2], who suggested that students can foster a better understanding of the knowledge if the materials are delivered with each encounter increasing in complexity and reinforcing previous learning. In addition to the engineering topics, our spiral curriculum also stresses the development of essential professional skills. Students go on to build substantial depth in mechanical engineering discipline starting in their junior year.

IntroM is normally taught at junior level. We have found that many students taking IntroM lack sufficient preparation in circuits, computer architecture and programming, the fundamental building blocks of mechatronics. However, occasionally we have come across some students who are exceptionally well prepared in these areas. The differences vary from year to year. There are several reasons for such discrepancies. First of all, the spiral foundation courses are taught by faculty members from the entire college of engineering. Even though the course syllabi are unified, the instructional practices and the emphases of teaching contents may vary based on each instructor's expertise. Secondly, there are also junior students transferred from other universities. They satisfy the pre-requisites in general but may not have the exact background provided by our spiral curriculum. Furthermore, it is always unavoidable that some students choose this elective course not because they have genuine interests in mechatronics but due to some other factors such as instructor preference, course availability, schedule conflict, and so on. Therefore, their passions in learning this "non-typical" mechanical engineering course naturally vary greatly. In addition to the reasons explained earlier, we also believe that the availability of the broad course and project choices in high schools these days has also contributed significantly to the discrepancy in students' background.

Such diversity of backgrounds, in addition to the breadth of topics typically associated with mechatronics, impose a great challenge to the teaching of IntroM. Although there are some textbooks published on this subject and several open course sources are also available online, none of these can be readily adopted for our course. Our situation calls for a unique set of technical contents built on the depth and complexity of the knowledge and skills that our students have mastered from the spiral curriculum. In addition to the selection of the proper course contents and the development of the hands-on activities at the appropriate level for our students, we also need to adopt an adaptive instructional methodology that can more effectively engage the less prepared and less focused students without compromising the interest of the majority in 
class. If we strictly adhere to a fixed course syllabus, we might have seemingly achieved the predefined course objectives, but some students would likely stumble over the semester and not gain solid learning.

Most of the successful stories of adaptive teaching implementations are found in elementary and secondary educational settings. We hardly encounter any adaptive teaching practice in regular engineering education classrooms. This paper presents the details of the design and implementation of an adaptive methodology to teach IntroM. The success of the course delivery has provided a clear message to the community of engineering pedagogy researchers and practitioners that we should promote adaptive teaching in engineering education to respond to the drastic changes in today's society.

\section{Related Work on Adaptive Teaching}

To most effectively deliver IntroM to a class of learners different in a great many ways, adaptive teaching is implemented in the instruction. Adaptive teaching is built on a variety of learning theories, including mastery learning [3], aptitude-treatment interactions [4], the zone of proximal development [5], individual differences in learning [6], the model-scaffold-fade paradigm [7], the expertise reversal [8], and the assistance dilemma [9]. For example, educational research in the area of aptitude-treatment interaction has found that an instructional treatment is more effective if it is adapted according learner's characteristics such as prior knowledge or interests [10, 11]; and mastery learning is an effective way of adapting teaching to individual students' knowledge growth [12].

Although the idea of adaptive teaching is not new, it is seldom implemented in regular instructional practice in college engineering education. There are many barriers to the implementation, including resource demands (such as the need for frequent formative assessment), practical challenges for instructors (such as individualized remedial instruction), and most importantly, a perception of unfairness since different students are assigned different work to accomplish the same learning outcomes [13].

In recent years the emergence of advanced learning technologies such as intelligent tutoring systems (ITSs) has overcome some of these barriers [14]. An ITS is a computer system that can provide immediate adaptive instruction to students without requiring intervention from a human teacher. There are many successful examples of ITSs being used in formal education settings. For example, a cognitive mastery approach implemented in intelligent tutoring software has been shown to substantially enhance student learning [15]. ActiveMath, a web-based adaptive learning environment for mathematics, has also demonstrated success for improving long-distance learning, for complementing traditional classroom teaching, and for supporting individual and lifelong learning [16].

However, most of the successful stories of these adaptive teaching implementations are found in elementary and secondary educational settings. In regular engineering education classrooms, we hardly encounter any adaptive teaching practice. The prominent reason is that most of the engineering professors still hold tightly on to the traditional teaching philosophy. Course design still follows the one-content-fit-all kind of 
traditional approach. Many engineering programs have actively responded to the progress of industrial development and have adjusted their curricula accordingly. Nevertheless, not enough change has been made to react to the drastic changes in today's high school education. A high school graduate who scored A in Advanced Placement (AP) History but without taking AP Physics could be accepted into an engineering program. This student's prior knowledge in engineering is bound to be very different from someone who took engineering related APs in high school. Same difference could exist between someone who was active in running robotics clubs in high school with someone who was engaged in student governance. Now all these students are sitting in the same classroom in college. To teach a class with such a diversity in knowledge preparation, plus other characteristic difference, adaptive teaching is inevitably the approach we need to adopt for an optimal learning result.

\section{Methods}

\subsection{Finding the background}

We adopt the "scaffolding" metaphor originated from the socio-cultural theory to teach IntroM in an "adaptive" manner. "Scaffolding" emphasizes a dynamic intervention finely tuned to student's ongoing progress [7, 17]. The support given by the instructor is adjusted depending upon the characteristics of the instruction situation and the responses of the students. Hence in a scaffolding learning environment, the teaching contents may vary in different situations. Our goal is to construct a solid "scaffold" foundation on which students can further build their learning.

In order to provide such a scaffolded learning environment to enable the students to develop both confidence and ability to pick up new knowledge and skills, we need to know where their current knowledge foundations lay and how different their preparations are. Hence the course starts with a background survey (Appendix) as well as a short quiz. This survey aims to evaluate their hands-on experiences in circuits and coding. To have students' learning interests in mind, some open-ended questions are given in the survey to understand their expectations of the course and their career goals. The goal of the short quiz is to test their knowledge in circuits, coding, sensing, actuation, as well as their general understanding in mechatronics.

In addition to helping the instructor find the background of the students, the short quiz also helps the students to identify their own strengths and weaknesses in different areas in mechatronics, whereas the survey provides a sense of how strongly everyone wants to be challenged in the hands-on activities. The students then go on to form well-balanced teams to work on the labs and projects for the rest of the semester.

\subsection{Design of course contents}

Design-loop adaptation: Selection of course contents. Adaptive teaching starts from course design, which is named as design-loop adaption in the literature [13]. It means redesign of a course as a result of discovering deficiencies in the knowledge 
component model that underlies the instruction. The survey and short quiz results have provided a clearer picture of the knowledge background and interests of our students. We thus have a better idea of how the "scaffold" of the course contents should be constructed to enable a more effective learning experience. Other important facts taken into consideration for the course content design include the syllabi of the pre-requisite courses of IntroM, the syllabi of the other courses required in the Mechatronics Concentration, the ABET (Accreditation Board for Engineering and Technology) requirements, and the industrial perspectives on mechatronics [18]. The final list of the course materials is drawn from different types of references including the textbooks on mechatronics $[19,20]$, Arduino website [21], and other open course resources $[22,23]$.

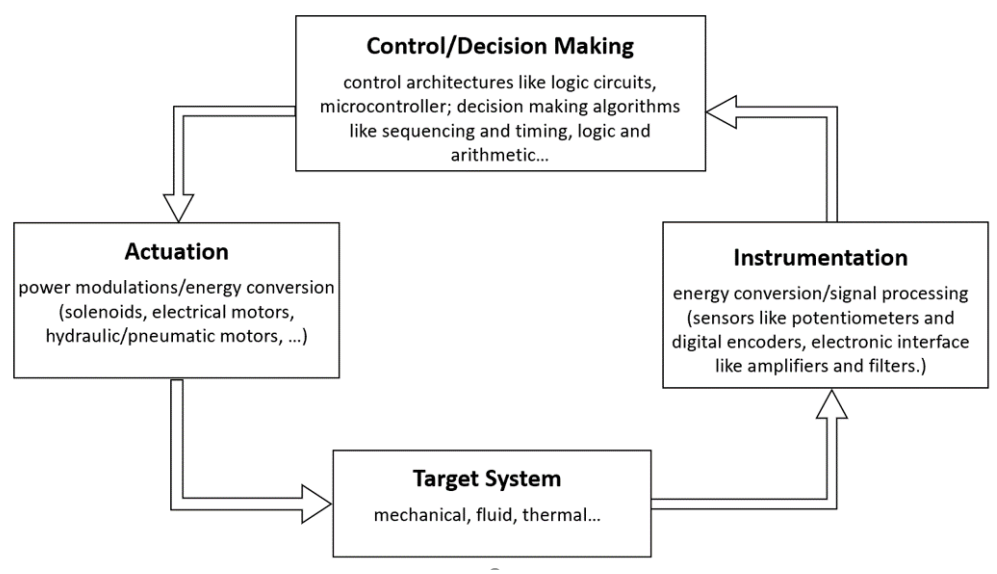

Fig. 1. Block diagram of a mechatronic system

The reason for picking these topics can be better explained by making using the block diagram of a typical mechatronic system as shown in Fig. 1. There is a 2-credit course Instrumentation Lab in our mechanical engineering curriculum covering the "Instrumentation" component in the block diagram, and a 3-credit course System Dynamics and Control concentrating on the "Control/Decision Making" requirement. As for the "Target System", we pick a 3-credit Introduction to Robotics as the final exit course of Mechatronics Concentration. Hence, IntroM is designed to cover the rest of the blocks in the diagram, namely "Computation", "Actuation" and "Interfacing" connecting the analog and digital worlds. By arranging the teaching materials as such, we can cover the large scope of the topics associated with mechatronics as a whole.

While the topical contents listed in Table 1 are mostly covered every time when the course is taught, the breadth and depth of the knowledge contents are delivered in an "adjustable" manner. Sometimes the adjustment is made for the entire class, whereas most of the adaptation is placed at the individual level for the optimal learning outcome. As indicated in the last column in Table 1, individual level adaption is incorpo- 
rated in most of the topics. The occurrence of the run-time adaption is determined based on the assessment of a student's knowledge state.

Task-loop adaptation: Scaffolding learning. In commercially available tutoring software such as Cognitive Tutor [24], the system dynamically assesses student knowledge state. Based on the assessment result, the system then selects learning tasks with knowledge components that the student has not yet mastered. There is good evidence that this adaptive task selection approach can substantially improve the effectiveness and efficiency of student learning, compared to giving all students the same problem set [15]. This section explains how the course content is delivered using task-loop adaptation through scaffolding student learning. Scaffolding is breaking up the learning into chunks according to student mastery and then providing a concrete structure for each chunk [7, 17].

Table 1. Course structure

\begin{tabular}{|c|l|l|l|}
\hline Week & \multicolumn{1}{|c|}{ Topics } & \multicolumn{1}{|c|}{ Items due } & Adaptation \\
\hline 1 & Introduction to mechatronic systems & Survey + HW1 & \\
\hline 2 & Review of analog circuits & Short quiz & \\
\hline 3 & Semiconductors - diode & Lab1 & Yes \\
\hline 4 & Semiconductors - transistor & Lab2 & Yes \\
\hline 5 & Boolean algebra/Binary numbers/Exam 1 & HW2 + Lab3 & Yes \\
\hline 6 & Digital circuits - combinational & & \\
\hline 7 & Digital circuits - sequential & HW3 + Lab4 & Yes \\
\hline 8 & Spring/Fall break & & \\
\hline 9 & Data acquisition - AD converter & Project 1 + HW4 & Yes \\
\hline 10 & Data acquisition - DA converter /Exam 2 & HW5 & \\
\hline 11 & Microcontroller & Labs5,6 & Yes \\
\hline 12 & Microcontroller & Labs7,8 & Yes \\
\hline 13 & Actuators/Microcontroller & HW6 & Yes \\
\hline 14 & PZT smart materials - optional topic & Labs9,10 & Yes \\
\hline 15 & Project competition & Final project & \\
\hline 16 & Reading day/Final exam & & \\
\hline
\end{tabular}

*HW $=$ homework

Topics 1 and 2: Since the majority of the students have insufficient background in electronics, computer architecture and coding, it is natural for them to feel intimidated when taking IntroM. It is very important to help them to build the confidence and overcome the "fear" for electronics and coding. Therefore, even though the course is already quite dense, we still dedicate the second week to reviewing the basics of ana$\log$ circuits. It is noted that no review topics are determined beforehand. The lesson usually starts with several simple exercises to exam some fundamental concepts. The poorly answered ones will be picked on the spot as the topics for the lesson of day. Sometimes there is not enough time to go through all the topics needed review. A list of video links will then be provided right after the class to the students so that they can independently finish reviewing the materials outside of classroom.

Topic 3: Every year the background survey reveals that most of the students have never used transistors before, and only a few of them have played with LEDs (light 
emitting diodes); that is they have no knowledge of semiconductor devices. IntroM therefore designates two weeks on diodes, transistors and their applications. The observed difficulties that students have in analyzing semiconductor circuits further prove the necessity for the revision of analog circuits in the previous lesson. That review serves as a "scaffold" for this step of learning.

Topics 4 and 5: Digital circuits are the basic building blocks in computer architecture. An introduction of digital circuits can help students to gain a more thorough understanding of how microprocessors interact with external devices. We thus decide to spend a week on combinational circuits and another week on sequential circuits. We have also found that adding a brief introduction of Boolean algebra and binary number system can make the teaching of logic circuits more effective. The survey results also suggest that this additional effort is necessary since most students have never learnt or simply forgotten Boolean algebra and binary numbers.

Topic 6: Analog to digital and digital to analog (ADDA) conversion provides the interface between the analog world and the digital brain; it is therefore a center piece in any mechatronics course. The introduction of the digital circuits has provided the students a good foundation to understand the architecture of ADDA. Starting with an explanation of the operation of op-amp comparator, we are able to cover ADDA in two weeks. However, before the introduction of ADDA, the class is given a short knowledge assessment on op-amp. The necessity of covering op-amp, and how much details needed is adaptable based on the assessment outcome. The sampling and aliasing concepts have been taught in a prerequisite course, so we focus more on the hardware of the device. Having learnt the architecture of ADDA converters in this course, students can now better digest the concepts such resolution and quantization.

Topic 7: Prior to IntroM, most of our students have had only a few weeks of programming basics in VBA (Visual Basic for Applications) in a sophomore-level course. Since they have no further experience in programming, we choose Arduino $\mathrm{UNO}$ as the platform to teach the concepts of microcontroller (Arduino). It is widely recommended that the UNO is the best board to get started with electronics and coding. We spend about three to four weeks teaching microcontrollers, depending on the students' progress. While the other topics in this course are taught using lecture-thenlab approach, in microcontrollers, lectures and labs are taught in parallel.

From the past few rounds of teaching experiences, it is evident that students have shown the most significant discrepancy in this topic. This is most likely caused by their different high school experiences such as robotics club activities, AP classes, or personal hobbies. Without implementing the adaptive teaching approach, it is impossible to achieve meaningful teaching results. The "advanced" programmers will find the coding too simple and lose interests whereas the opposite group with no programming experience will find the same exercise unmanageable and lose confidence.

To deliver this topic effectively, task-loop adaptation is made at various levels. After the initial assessment of their ability in coding, students are organized into three groups. For the most advanced group, the coding and wiring exercises are made more challenging to ensure they are highly engaged. Bonus questions are designed for this purpose. The least experienced group are invited for remedial lessons. The remedial lessons can take the form of one-on-one tutoring, group tutoring, or watching a care- 
fully picked open-source links. Relatively simple coding and wiring exercises are designed for this group. The focus of this design is placed on boosting their confidence and inspiring their interests.

Topic 8: While teaching microcontrollers, we also introduce the topic of actuators. We mainly focus on the principles of DC motor, DC motor servo drive, and interfacing of DC motor with microprocessor. Sometimes we have ample time to discuss the modeling of DC motors as well. However, if we have no time to cover modeling in this course, we will move the content to System Dynamics and Control, which is a sequel course to IntroM in our Mechatronics Concentration.

Topic 9: In the last week of teaching, we normally need to adapt between an introduction of PZT (piezoelectric transducer) smart materials or a review of all the materials covered in the semester. Piezoelectric effect is the ability of smart materials to generate an electric charge in response to applied mechanical stress; thus PZT is the perfect choice for micro-mechatronic devices. Since micro-mechatronics is an emerging technology, we feel there is a need to give our students an introductory briefing. However, if we see the necessity of a comprehensive review of the class, the priority of the last week will be placed on that.

\subsection{Labs and projects with adaptable tasks}

Table 2. List of hands-on activities

\begin{tabular}{|l|l|}
\hline \multicolumn{1}{|c|}{ Labs Adaptation } & \multicolumn{1}{|c|}{ Group 1 } \\
\hline \multicolumn{2}{|c|}{ Projects } \\
\hline Lab1. Basic skill preparation Yes & \\
\hline Lab2. Rectifiers using diodes & \\
\hline Lab3. Bipolar junction transistor characterization 2 \\
\hline Lab4. Exploring 74HC74 D Flip Flop & \\
\hline \multicolumn{2}{|c|}{ Groun counter } \\
\hline Lab5. Getting started with Arduino on Windows & \\
\hline $\begin{array}{l}\text { Lab6. Turning an LED on and off Yes } \\
\text { Lab7. Debouncing a switch with Arduino Yes }\end{array}$ & \\
\hline Lab8. Working with an IR sensor Yes & \\
\hline Lab9. Using PWM to control an actuator Yes & 2. Mobile robot navigation \\
\hline Lab10. Light up a seven-segment display Yes & \\
\hline
\end{tabular}

Many universities have recognized the importance of teaching mechatronics using a hands-on approach. MIT has included lab experiences that teach mechatronics principles across all level of instruction [25]. Georgia Tech has instituted an interdisciplinary approach to mechatronics, teaching a variety of courses in a mechatronic lab facility [26]. Aimed at helping our students to develop a strong intuition about electronic circuits and microprocessing, IntroM has been structured to also include a significant experimental component. We believe learning by doing tends to add motivation to the underlying analytical materials, resulting in higher knowledge retention, and also better preparation of students for future mechatronic experiences. 
Students taking this course are required to purchase Super Starter Kit UNO R3 Project [27], which costs around $\$ 35$. This kit has most components needed for the hands-on activities except the last project. As shown in Table 2, throughout the semester we offer total 10 hands-on activities that are closely tied to the topical contents covered in the lectures. The complication of each activity varies depending on the topics. Since the students have the kit, they can continue to work on the activities outside of class hours. This arrangement adds a lot of adaptability to the teaching.

Group 1 labs: The first group of labs focuses on practices on digital circuits. Lab 1 requires students to review the basic skills by watching some videos, including how to use a breadboard, read resistors, and operate electronic devices such as oscilloscopes and function generators. Since many students should have taken Analog Circuits and Instrumentation Lab as pre-requisites, we expect them to have some basic skills in analog circuits. This lab is thus made as an optional requirement to be completed outside of class. If students feel confident in handling those devices, they can choose not to watch the videos. The next two labs emphasize on the understanding and application of semiconductor devices. The students can directly observe the characteristics of semiconductor devices by completing these labs. Lab 4 requires them to construct a simple digital circuit to demonstrate the logic of the 74HC74N D flip flop. This lab serves as a precursor to the first project, which requires them to design and build a binary counter.

The requirement of Project 1 is designed to be adaptable. The high-performance group is required to build a 4-bit binary counter by designing the circuit themselves. For the group on the other performance extreme, the project requirement is to build a 2-bit binary counter by providing them the circuit. Students are given two weeks to complete the project outside of class hours while the lectures continue.

Group 2 labs: The second group of labs are structured around a comprehensive second project, that is to assemble a mobile robot and navigate it using Arduino. The mobile robot is required to track a line marked on a table. When the robot runs to the edge of the table, it must stop moving forward and retract. The other required task is to detect obstacles and react accordingly. Depending on the locations of the obstacles, the robot should make the decision to turn left, right, or retract. Students need to use Arduino to read sensors, then control the motions of motors according to the sensor readings. Labs 5 to 10 are all designed to prepare them for the final project. Together with the lectures, Labs 5 to 7 emphasize the basics of the hardware and software of a microcontroller, in this case, Arduino UNO. Labs 8 and 9 demonstrate how the sensor/actuator interacts with Arduino through ADDA. Lab 10 requires the students to code different types of loops so that they are ready to take up the coding challenge in the final project.

It is noted that Labs 6 to 10 are all designed with adaptable tasks. Students can choose to complete the labs following different paths: they can write the code from scratch, they can choose to work on pseudo code, or they can select the easiest path in which the code framework is provided and only some blanks need to be filled in. It is observed that in the beginning more students prefer the easiest path. But once the confidence is developed, more students will switch to the challenging path. 
Final project: For Labs 1 to 10, students are encouraged to work in teams of two. However, for the final project, students are allowed to form groups of 3 or 4 to work due to its complexity. They are given 3 weeks to complete the project. In the first week they focus on the assembly of the mobile robot, including assembling the body of the robot, building the control circuit, and installing sensors and motors. The fully assembled mobile robot is shown in Fig. 2 (picture taken from ELEGOO website [27]). In the second week, they work on the Arduino sketch to control the mobile robot for line tracking and obstacle avoidance. In the last week, every mobile cart is tested in the same location, with the same lighting condition and same tracking marks.

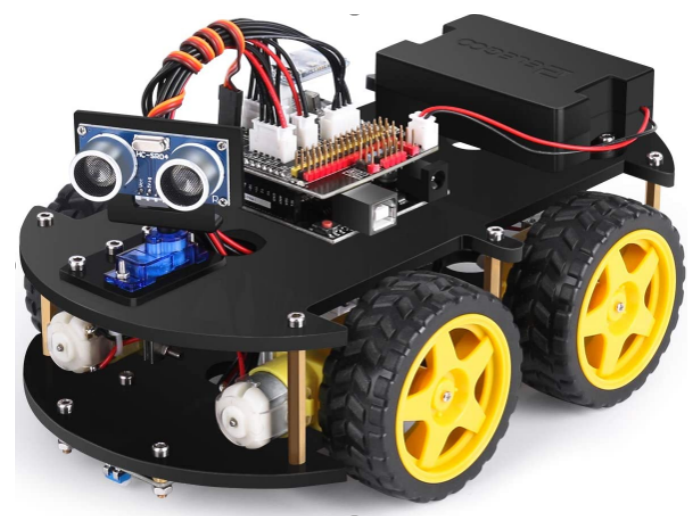

Fig. 2. Mobile robot

Students are encouraged to be creative and add more features to the robot to earn bonus points. For example, the robot can be made to trigger a warning signal when an obstacle is near, it can display the "mileage" of motion, or it can be controlled using a remote. On the due date of the project, a competition is held. The winning criteria include success of line tracking, edge detection, obstacle avoidance in all directions, the time to complete the required navigation, and creativity for the design.

The past experiences have shown that the project has been very successful overall. Despite the relatively short period of coding time given, all mobile robots were able to complete the navigation tasks. The students exhibited a high level of enthusiasm in this project. Some groups enriched their final products with all sorts of interesting decorative ideas ([28] shows a sample mobile robot decorated as a pirate ship).

\subsection{Evaluation}

Both quantitative ratings and qualitative feedback have been studied carefully for course improvement. Towards the end of a semester, usually students are overly measured with all sorts of surveys. To avoid overburdening them with excessive survey, which likely leads to false information in measurement data, the course evaluation questionnaire used has been a general one required by the university, with no specifically designed question targeting at this course. By analyzing the results over 
the years, we believe that the general questionnaire provides enough critique for teaching reflection and improvement for this course.

\section{$4 \quad$ Results}

In the past four rounds of offering of IntroM, the class size varied from 17 to 27 , with 22 students per class on average. The overall ratings of the course have increased steadily; from 3.4 on a 5-point scale for the first time of teaching, to 4.0, 4.3, and 4.5 in the most recent offering. While a swift look at student ratings may represent a trend of improvement, a qualitative study of the comments can provide more insightful information. A detailed qualitative analysis of the comments for this course is discussed from several perspectives below. It is noted that not all students write comments in course evaluation, and not all comments contain constructive critiques or suggestions. The number of meaningful comments varies across different perspectives discussed here. For a succinct presentation purpose, in each perspective, only the three most representative comments are selected for analysis.

\subsection{Do the students meet the prerequisites?}

In the first two rounds of teaching this course, we received the following feedback relating to the prerequisites of this course:

The instructor "got handed a classroom of students who were not prepared to take this class - despite having taken the required prerequisites. This led to spending a lot of time on topics that should have been a brief review."

"And then on top of it (not well prepared), a lot of the class had no interest in learning."

"a lot of assumptions were made about the knowledge or topics relating to electronics that mechanical students didn't know."

Such feedback, together with the "ground-checking" quiz results, have further confirmed our observation that there is a great variety in the students' backgrounds. Some are much better prepared than others, and some show much stronger interests in the course.

\subsection{Has the course provided a balanced content?}

In order to accommodate such differences, we have made the course contents adaptable to best suit various abilities. For the better prepared students who want to challenge themselves, we provide them additional learning materials. For those less prepared and less enthusiastic, the main focus is placed on motivating them, rather than making them feel intimidated.

This adaptive teaching strategy has proven to be effective through the following student feedback, where better prepared students acknowledged the challenge and the rest felt the materials digestible and interesting: 
"I felt appropriately challenged by the course. I did have the advantage of being familiar with Boolean algebra and Arduino programming beforehand; however, these concepts were taught well, providing enough information for a mechanical engineer to be able to generally understand how mechatronic systems work."

The instructor "did an excellent job introducing the course material to us, some of the material we were familiar with and some we were not, and she was the best in outlining those material we first encounter."

"This course had many interesting topics and was taught in a very digestible manner."

\subsection{Can the students cope with the heavy course load?}

Mechanical engineering students largely have insufficient preparation in electronics and programming. It has always been a difficult task trying to cover all the intended topics in mechatronics and meanwhile complete a large number of labs and projects. However, by adopting this adaptive teaching approach, students felt positive about the heavy load in general:

"This class has made me put more effort in understanding the content more than any other class. It has enhanced my understanding on electronics and how they are integrated into systems along with mechanical components."

The instructor "did an excellent job with the course. Although the material can be difficult, she provided plenty of projects and assignments for students to build up their grades."

"The atmosphere within the course elevated my desire to comprehend the mechatronic coursework. Despite the challenges regarding the workload, it was a friendly environment and by far one of the best instructors I have had."

\subsection{Can the students take on the challenge in hands-on activities?}

The background survey results indicate that about 20-30\% students each class have less experience in electronics and coding. They feel intimidated by the content of hands-on activities. To provide a scaffold to these students, we start from the very basic building blocks of microprocessor when designing the lab materials. When forming teams for hands-on activities, we also make sure that there is a good balance among team members so that everybody can get the most out of the learning.

Overall, students seemed to find the practical applications in this course had enhanced their learning. There has never been a negative comment on the hands-on activities. Instead, the enjoyment and benefit of these experiences are explicit:

"I enjoyed how it was practical. It took us from the building blocks of how computers actually function to applying what we had learned to make working circuits. I wish more classes were structured this way."

"The course with labs was a great way to demonstrate the practicality of mechatronic systems."

"I liked the class as a whole. It was nice to learn about the theory and then apply what we learned in labs." 


\subsection{Has the course conveyed the concept of "integration"?}

The main objective of IntroM is to emphasize the concept that mechatronics combines in a synergetic way the classical engineering disciplines, mechanical and electrical engineering and computer science, leading to new products. The course is designed to help the students to establish the connection between mechanical engineering, a discipline that they are familiar with, and electrical engineering, a discipline that appears to be remote to them in our curriculum setting. After taking the course, the understanding of the integration between mechanical and electrical engineering is evident in the evaluation results. Another positive feedback is that this course has led them step into the world of electronics which frightened them in the beginning:

"What I liked about the course is that I feel I have gain knowledge in a

different field than mine. The course taught me the relationship between mechanical engineering and electronic engineering which will definitely help me in the work field."

"The course balanced theory and practice very well, and was aimed directly at mechanical engineers who only need to know the basics of a wide variety of electronic principles."

"I enjoyed the practical applications of the course. The labs in particular were insightful into a world of micro-controllers that I didn't know existed. And it turns out that the equipment was all very accessible."

\subsection{Has the course inspired their interests in mechatronics?}

Analysis of the background survey shows that about 30\% students initially have interests in mechatronics, but almost none explicitly writes that they want to work in the field. The most encouraging feedback from the evaluation lies in the fact that their interests in the broad field of mechatronics are inspired by the course:

"It was a challenging course but overall I have left the course with a desire to further my mechatronic skills and knowledge."

"I am so pleased and thankful to (the instructor) for the valuable knowledge I have gained, and I'm looking forward to taking her robots class next semester."

"I really enjoyed learning about the material in the course, I may become an automation engineer one day in future now."

\subsection{What are the suggestions for improvement?}

There are many constructive suggestions regarding the improvement to be made. In terms of the criticism on teaching contents, the most frequent feedback concerns the amount of coding covered in this class. Perhaps it is due to the fact that most of them have little or no experience in coding before, such as this comment:

"I have never done a coding before, by doing the labs (the instructor) assigned and having her instantaneous help during the lab I have understood tips of righting a code" 
Therefore, many of them suggested that:

"I wish the labs were more spread out, and we spent more time in class to understand the coding. I also thought the class would spend more time on the Arduino/programming aspect of mechatronics instead of focusing on circuit analysis."

"I overall enjoyed it, but wish the course had more labs or focused more on Arduino/similar applications."

\section{Conclusion}

In this paper we present our investigation in using an adaptive methodology to teach Introduction to Mechatronics to non-traditional mechanical engineering students at a private university in America. We detail the setup of the course contents and the hands-on activities. We believe due to the fact that the students demonstrate a variety of backgrounds in their academic preparation and other characteristics, adaptive teaching approach should be adopted in course design and delivery. The course contents are made adaptable according to the background survey conducted in the beginning of a semester. Since the lecturing materials and labs/projects are tailored to suit the ability of each specific group of students, we can engage the otherwise less prepared and less interested students while also challenging the students with better preparation and enthusiasm. The positive course evaluations have proven the success of this teaching approach.

However, there are rooms for improvement for future study. Even though the students have enjoyed the hands-on activities in general, they have indicated that more coverage on Arduino coding is demanded. How to balance the materials in an already dense mechatronics courses remains challenging. In future perhaps we can move the revision of the prerequisite knowledge online to open up more space for programming.

Another area that could be improved is the assessment of student performance. Most current adaptive teaching practices are software based. The assessment is automatically completed by those intelligent tutoring systems. Typically, the software developers hire a large group of programmers, psychometricians, and content experts to develop the assessment system. For a small classroom setting where an ad-hoc adaptive teaching is implemented, we need to develop a more systematic method for grading to ensure a fair and reliable assessment.

Last but not least, the result of teaching effectiveness will be more convincing if there is a control group involved for statistical comparison. Since our class size is only 22 on average, practically it is not feasible to split the already small class into intervention and control groups. From educational research perspectives, however, if we can pair up with a sister institution to form a sizable control group, we will be able to draw more meaningful research findings through comparison.

Regardless of the abovementioned weaknesses, we are entirely convinced that we should promote adaptive teaching in engineering education for the 21 st century. With the evolution of technology, secondary education, industry and society, the traditional 
one-content-fit-all kind of instructional approach can no longer effectively teach a class with a wide range of diversity.

\section{References}

[1] Daniels, S., Aliane, B., \& Collura, M. (2004). Development of a multidisciplinary engineering foundation spiral. Proceedings of the 111th American Society for Engineering Education Annual Conference. Salt Lake City, Utah. https://doi.org/10.18260/1-2--13080

[2] Bruner, J. (1966). Toward a theory of instruction. Cambridge, MA: Harvard Univ. Press.

[3] Bloom, S. (1968). Learning for mastery. Evaluation Comment, (UCLA-CSIEP), 1(2), 112.

[4] Cronbach, L., \& Snow, R. (1977). Aptitudes and instructional methods: A handbook for research on interactions. New York: lrvington.

[5] Vygotsky, L. S. (1978). Mind in society: The development of higher psychological processes. Cambridge, MA: Harvard University Press.

[6] Jonassen, D. H., \& Grabowski, B. L. (1993). Handbook of individual differences, learning, and instruction. Hillsdale, NJ: Erlbaum.

[7] Collins, A., Brown, J. S., \& Newman, S. E. (1989). Cognitive apprenticeship: Teaching the crafts of reading, writing, and mathematics. In L. B. Resnick (Ed.), Knowing, learning, and instructions: Essays in honor of Robert Glaser (pp. 453-494). Hillsdale, NJ: Lawrence Erlbaum Associates. https://doi.org/10.4324/9781315044408-14

[8] Kalyuga, S. (2007). Expertise reversal effect and its implications for learner-tailored instruction. Ed. Psychology Review, 19(4), 509-539. https://doi.org/10.1007/s10648-007$\underline{9054-3}$

[9] Koedinger, K. R., Pavlik, P., McLaren, B. M., \& Aleven, V. (2008). Is it better to give than to receive? The assistance dilemma as a fundamental unsolved problem in the cognitive science of learning and instruction. In B. C. Love, K. McRae, \& V. M. Sloutsky (Eds.), Proceedings of the 30th Annual Meeting of the Cognitive Science Society (pp. 21552160). Austin, TX: Cognitive Science Society.

[10] Snow, R. (1989). Aptitude-Treatment Interaction as a framework for research on individual differences in learning. In P. Ackerman, R.J. Sternberg, \& R. Glaser (Ed.), Learning and Individual Differences. New York: W.H. Freeman.

[11] Kalyuga, S., Ayres, P., Chandler, P., \& Sweller, J. (2003). The expertise reversal effect. Educational Psychologist, 38(1), 23-31. https://doi.org/10.1207/s15326985ep3801_4

[12] Kulik, C., Kulik, J.A., \& Bangert-Drowns, R.L. (1990). Effectiveness of mastery learning programs: A meta-analysis. Review of Educational Research, 60(2), 265-299. https://doi.org/10.3102/00346543060002265

[13] Aleven, V., McLaughlin, E. A., Glenn, R. A., \& Koedinger, K. R. (2017). Instruction based on adaptive learning technologies. In R. E. Mayer \& P. Alexander (Eds.), Handbook of research on learning and instruction (2nd Ed., pp. 522-560). New York: Routledge.

[14] VanLehn, K. (2011). The relative effectiveness of human tutoring, intelligent tutoring systems, and other tutoring systems. Educational Psychologist, 46(4), 197-221, https://doi.org/10.1080/00461520.2011.611369

[15] Corbett, A., McLaughlin, M. and Scarpinatto, K. C. (2000). Modeling student knowledge: Cognitive tutors in high school and college. User Modeling and User-Adapted Interaction, 10(2-3), 81-108. https://doi.org/10.1023/a:1026505626690

[16] Melis, E., \& Siekmann, J. (2004). Activemath: An intelligent tutoring system for mathematics. In R. Tadeus- iewicz, L.A. Zadeh, L. Rutkowski, J. Siekmann, (Eds.), 7th Interna- 
tional Conference "Artificial Intelligence and Soft Computing” (ICAISC) Lecture Notes in AI LNAI 3070 (pp. 91-101). Springer-Verlag. https://doi.org/10.1007/978-3-540-24844$\underline{6} 12$

[17] van de Pol, J., Volman, M., \& Beishuizen, J. (2010). Scaffolding in teacher-student interaction: a decade of research. Ed. Psychology Review, 22(3), 271-296, https://doi.org/10.1007/s10648-010-9127-6

[18] Kyura, N., \& Oho, H. (1996). Mechatronics-an industrial perspective. IEEE/ASME Transactions on Mechatronics. 1(1), 10-15. https://doi.org/10.1109/3516. 491405

[19] Cetinkunt, S. (2015). Mechatronics with experiments (2nd Ed.). Hoboken, New Jersey: John Wiley \& Sons.

[20] Alciatore, D. (2019). Introduction to mechatronics and measurement systems (5th Ed.). New York: McGraw-Hill.

[21] Arduino. Retrieved from https://arduino.cc/

[22] ME588: Mechatronics. (2020). Retrieved from https://engineering.purdue.edu/ME588/Lec tureNotes/

[23] PyroElectro.com. (2020). Retrieved from http://www.pyroelectro.com

[24] Cognitive Tutor. (2020). Retrieved from https://ies.ed.gov/ncee/wwc/Docs/Intervention Reports/wwc cognitivetutor 062116.pdf

[25] Trumper, D. L., \& Ludwick, S. J. (1999). Development of 2.737 Mechatronics at MIT. Proc. of IEEE/ASME Int. Conference on Advanced Intelligent Mechatronics. Atlanta, GA. https://doi.org/10.1109/aim.1999.803210

[26] Arkin, C., Lee, K., McGinnis, F., \& Zhou, C. (1997). The development of a shared interdisciplinary intelligent mechatronics laboratory. J. of Eng. Ed., 86(2), 113-118. https://doi.org/10.1002/j.2168-9830.1997.tb00273.x

[27] ELEGOO UNO Project Super Starter Kit with Tutorial and UNO R3 Compatible with Arduino IDE. Retrieved from https://www.amazon.com/ELEGOO-Project-TutorialController-Projects/dp/B01D8KOZF4

[28] Campus News (2019). Engineering Students Make a Splash with Unique Pirate Ship Robot. Retrieved from https://www.newhaven

\section{$7 \quad$ Author}

Cheryl Q. Li is an Associate Professor of Mechanical Engineering at University of New Haven, 300 Boston Post Road, CT 06516, USA. She has unique crossdisciplinary educational backgrounds in Mechatronics Engineering and Educational Psychology. In her career path, she has gained extensive research experience in Mechatronics, Robotics, Control, Engineering Design, and Artificial Intelligence. She has taught a broad range of courses in general engineering, kinematics and dynamics, systems and control, robotics and mechatronics at universities in Australia, Singapore, and US. She has also accumulated a rich experience in international joint degree program coordination and international student supervision. Email: cli@newhaven.edu

Article submitted 2020-05-28. Resubmitted 2021-01-29. Final acceptance 2021-02-02. Final version published as submitted by the authors. 


\section{Appendix. Background Survey}

\subsection{Survey on hands-on experience}

Table 3.

\begin{tabular}{|c|l|c|c|}
\hline Items & \multicolumn{1}{|c|}{ Experiences } & No & Yes (How many hours?) \\
\hline 1 & Have you used breadboard before? & & \\
\hline 3 & Have you done soldering before? & & \\
\hline 4 & Have you used oscilloscope before? & & \\
\hline 5 & Have you used diode before? & & \\
\hline 6 & Have you used transistor before? & & \\
\hline 7 & Have you programmed a microprocessor before? & & \\
\hline 8 & If yes to Question 7, what type? & & \\
\hline 9 & Have you played with motors before? & & \\
\hline 10 & If yes to Question 9, what type? & & \\
\hline 11 & Do you have experience in digital circuits? & & \\
\hline 12 & Do you know what Boolean Algebra is? & & \\
\hline 13 & Were/are you involved in any robotics team? & & \\
\hline 14 & Do you know what is low/high pass filter? & & \\
\hline 15 & If yes to Question 14, have you done experiment? & & \\
\hline 16 & Do you have coding experience? & & \\
\hline 17 & If yes to Question 16, what type of software? & & \\
\hline
\end{tabular}

8.2 Why do you want to take this course (please circle your answer(s))

- I just need to satisfy the elective requirement

- I want to work in the field of automation/robotics/mechatronics in future

- I like to learn circuits, electronics, microprocessor and coding

- I like to build computer-controlled devices that can move around

- Other reasons please specify

- On the scale of 1 to 5 ( $5=$ the strongest), how you want to be challenged in the projects?
1
2
3
4

5

\subsection{Survey on concepts}

- Name two mechatronics products

- Describe your understanding of "mechatronics"

\subsection{Please add any comment / expectation from this course}

